\title{
Vajene Doğmuş Dev Submüköz Myomun Cerrahi Tedavisi: Olgu Sunumu
}

\author{
Surgical Treatment of A Huge Submucous Myoma Prolapsed Into The Vagina: Case Report
}

\author{
Yıldız Akdaş REİS ${ }^{1}$, Derya Akdağ CİRİK ${ }^{1}$, Tolga TAŞÇı ${ }^{1}$, Kerime Nazlı SALİHOĞLU ${ }^{1}$ \\ Nurettin BORAN ${ }^{1}$, Gökhan TULUNAY ${ }^{1}$, Taner TURAN ${ }^{1}$ \\ 1. Etlik Zübeyde Hanım Kadın Hastalıkları Eğitim ve Araştırma Hast. Kadın Hastaklıkları ve Doğum Bölümü, Ankara
}

\section{ÖZET}

Tüm myomların yaklaşık \% 5 'ini oluşturan submüköz myomlar, endometriumun hemen altındaki kas tabakasından kaynaklanırlar ve büyüdükçe uterin kaviteyi distorte ederler. Kavite içinde olan sapl submüköz myomlar ise, uterin kontraksiyonlarla bazen serviksten geçerek vajene kadar ilerleyebilirler. Vajene doğmuş myom diye adlandirlan bu myomların en sik tedavi şekli vajinal yolla yapllan myomektomidir. Ancak nadiren, myomun kavite içindeki bölümünü de çok büyük boyutlara ulaşırsa abdominal yaklaşım gerekli olabilir. Bu yazıda vajeni tamamen dolduran, kavite içinde de dev büyüklüğ̈̈ne ulaşan ve preoperatif dönemde yapılan manyetik rezonans görüntülemede leiomyosarkom şüphesi olan bir olgu sunulmuştur. Yaklaşık 2 aydır vajinal kanama şikayeti olan 45 yaşındaki multipar hastanın, yapilan spekulum muayenesinde vajeni tamamiyle dolduran $8 \mathrm{~cm}$ çapında kötü kokulu nekrotik bir kitlesi saptanmıştır. Uterusun 3 aylık cesamette olması $12 \mathrm{~cm}$ büyüklüğ̈̈ne ulaşan submüköz myom izlenmesi üzerine hastaya abdominal histerektomi yapılmiştır. Ancak myomun vajendeki bölümü abdominal olarak çıkarılamamıştır. Myom vajinay tamamiyle doldurmuş olduğundan bu kısım vajinal yolla eksize edilmiştir.

Anahtar Kelimeler: submüköz myom; histerektomi; cerrahi

\footnotetext{
İletişim:

Sorumlu Yazar: Derya Akdağ CiRik

Adres: Zübeyde Hanım Kadın Hastalıkları Eğitim ve Arş. Hast. Kadın Hastaklıkları ve Doğum Bölümü, Etlik, Ankara Tel: +90 (312) 5674000

E-Posta: deryaakdag@yahoo.com

Makale Geliş: 21.05.2015

Makale Kabul: 19.08.2015

DOI: http://dx.doi.org/10.16948/zktb.04689
}

\section{ABSTRACT}

Nearly 5\% of all myomas are originated from the smooth muscle of uterus, beneath the endometrium and called as 'submucous myoma'. Submucous myomas distort the cavity when they enlarge and may even pass the cervix and reach to the vagina by uterine contractions. The most common treatment of the myomas prolapsing the vagina is the vaginal myomectomy. However, abdominal treatment may be necessary when the submucous myom grow within the cavity and enlarge the uterus. This paper presents a case of huge submucous myoma with a suspician of leiomyosarcoma in the magnetic resonance imaging, that grow into very big size within the cavity and completely fill the vagina. A 45-years-old multiparous women with a complaint of vaginal bleeding was diagnosed to have a $8 \mathrm{~cm}$ necrotic submucous myoma prolapsed into vagina after pelvic examination with speculum. Due to the combination of malignancy risk and uterus with three-month gravida size, abdominal exporation with laparotomy was planned for the patient. In the abdominal exploration, a $14 * 13 * 12 \mathrm{~cm}$ submucous myoma growing into the endometrial cavity was observed and abdominal hysterectomy was planned. After completion of abdominal hysterectomy, vajinal part of myoma was tried to extract abdominally but it could not. Due to the complete replacement of vaginal cavity by the myoma, vajinal part of myoma can only be extracted by vaginal approach.

Keywords: submucous myoma; hysterectomy; surgery 


\section{GíRIŞ}

Uterusun en s1k benign tümörü olan leiomyomlar uterusun kas tabakasından kaynaklanırlar. Bulunduğu yere göre submüköz, intramural ve subseröz olarak sinıflandırılır. Submüköz myomlar, leiomyomların \%5'ini oluşturur (1). Kavitede bulunan saplı submüköz myom, uterin kontraksiyonlarla servikal kanaldan geçip vajene prolabe olabilir (2). Vajene doğmuş myoma sıklıkla eșlik eden iki komplikasyon enfeksiyon ve nekrozdur. Vajene doğmuş pedinküllü submüköz myomlarda tedavi genellikle vajinal yolla yapılan myomektomidir (3).

$\mathrm{Bu}$ yazıda ise preoperatif dönemde yapılan tetkiklerinde leiomyosarkom şüphesi olan ve laparotomi yapılan, fakat abdominal histerektomiye rağmen vajendeki bölümü abdominal yolla çıkartılamayan dev myomun vajinal yoldan çıkartıldığı bir olgu sunulmuştur.

\section{OLGU}

45 yaşında, 4 vajinal doğumu olan hasta, 2 aydır devam eden vajinal kanama şikayeti ile öncelikle başka bir hastaneye başvurmuş. Yapılan muayenesinde vajeni dolduran kötü kokulu kitle saptanan hastadan bu merkezde alt batın manyetik rezonans görüntüleme (MRI) tetkiki istenmiştir. Yapılan MRI'da 'uterusta korpus seviyesinde $14 \times 13 \times 12 \mathrm{~cm}$ boyutlarında, içerisinde kistik komponentleri bulunan, intravenöz kontrast madde enjeksiyonu sonrası kontrastlanan, endometrial kaviteyi antero-superiora doğru iten, uterusu ekspanse eden ve uterusta atrofiye neden olan dejenere leiomyosarkom ile uyumlu kitle lezyonu' tanımlanmıştır. Kitleden yapılan biyopsi sonucu 'nekrotik materyal' olarak raporlanmış. Hasta ileri tetkik ve tedavi için 'leiomyosarkom şüphesi' ile hastanemize refere edilmiştir.

Hastanın onkoloji kliniğimizde yapılan spekulum muayenesinde 'vajeni tamamen dolduran yaklaşık $8 \mathrm{~cm}$ çapında nekrotik kitle' gözlendi. Bimanuel muayenede ise uterus yaklaşık 3 aylık gebelik iriliğinde ve her iki adneks serbest olarak bulundu. Kitlenin vajeni tamamen doldurması, kalın pediküle sahip olması ve leiomyosarkom şüphesi olması nedeniyle operasyonun abdominal yaklaşımla gerçekleştirilmesine karar verildi.

Hastaya göbek alt1 medyan insizyonla operasyonun yapılacağı bilgisi verildi ancak hastanın bu konuda onamı alınamadığından Pfannenstiel insizyon tercih edildi. Hasta genel anestezi altında iken, litotomi pozisyonunda, uygun örtünme ve temizliği takiben bat1na Pfannenstiel kesi ile girildi. Yapılan batın eksplorasyonunda, intraabdominal organlar, omentum ve retroperitoneal bölge metastaz açısından negatif idi, her iki tüp ve overler ise normal görünümde ve uterus yaklaşık 3-4 aylık gebelik iriliğinde idi (Resim 1).

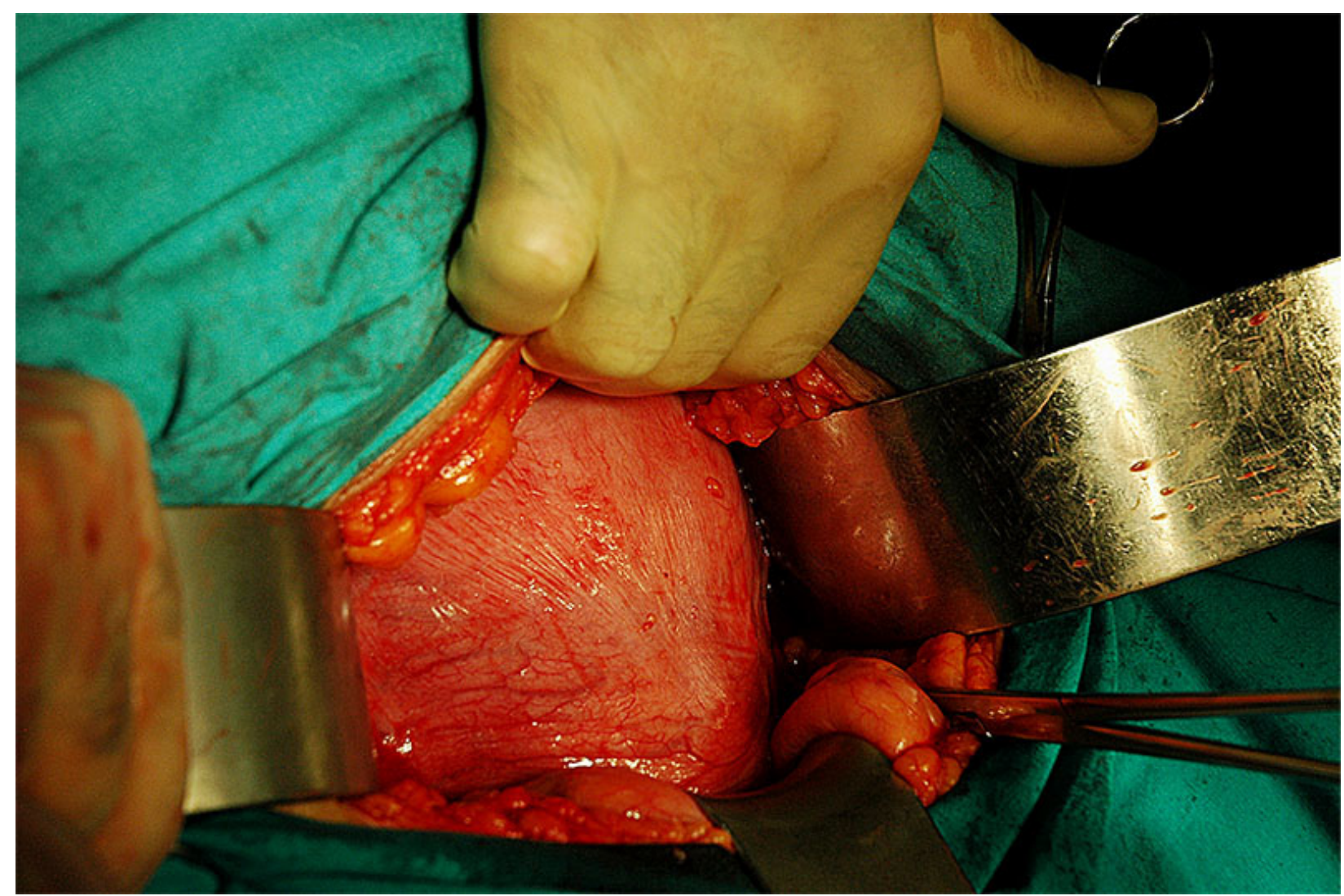


Vajinal muayenede ise, introitustan bașlayan üst ucu palpe edilemeyen yaklaşık $10 \mathrm{~cm}$ çapında myomatö kitle izlenmekte idi. Histerektomi sırasında endoservikal kanalı dolduran myomun sapına ulaşmak için serviksin ön duvarına transvers kesi yapılıp $T$ şeklinde insizyon ile uterin fundusa ulaşıldı (Resim 2).

Myomun yaklaşık $5 \mathrm{~cm}$ 'lik kalın bir tabanla fundusa oturmuş olduğu izlendi. Myomun vajinada kalan kısmı abdominal olarak çıkarılamadığından öncelikle kavite içindeki myom ç1karılarak frozen incelemesi için patolojiye gönderildi. Takiben abdominal histerektomi işlemi tamamlandı. Çıkarılan myomun boyutu $25 \times 15 \times 10 \mathrm{~cm}$ 'ydi. Materyalin intraoperatif patoloji sonucu 'malignite izlenmedi, mezenkimal tümör' olarak rapor edildi. Myomun vajende kalan ve vajeni tamamiyle doldurmuş olan parçası da vajenden ekstrakte edildi.

Sonrasında yapılan spekulum muayenesinde vajen yan duvarlarda laserasyonlar izlendi ve bu laserasyonlar tek tek sütürlerle onarıldı.

Operasyon sonrasinda erken komplikasyon izlenmedi. Hasta postoperatif 4. günde sorunsuz olarak taburcu edildi. Hastanemiz patoloji kliniğince incelenen kitlenin parafin blok sonucu 'dejenere ve enfekte leiomyom' olarak rapor edildi. Uterusta endometrit bulguları mevcut iken her iki tüp ve overde ise patoloji izlenmedi.

\section{TARTIŞMA}

Kadınların en sık görülen jinekolojik tümörü olan leiomyomlar genellikle asemptomatiktirler. Ancak, semptomatik kadınlarda ağır ve uzun süreli kanama en s1k görülen şikayettir ve özellikle submüköz ve intramural myomu olan kadınlarda da daha siklıkla izlenir $(1,3)$. Genellikle kavite içinde olan submüköz myomlar, nadiren büyüyüp servikal kanaldan geçerek vajene prolabe olabilir. Daha nadir görülen ve 'vajene doğmuş myom' olarak adlandırılan bu myomlar vajende bası hissine, pelvik ağr1ya veya enfekte olup kötü kokulu akıntıya da neden olabilir $(4,5)$. Sunulan olguda da vajeni tamamiyle dolduran bir myom olduğu halde belirgin şikayet 2 aydır süren vajinal kanama idi. Myomların tanısı klasik olarak vajinal muayene ve ultrasonografi ile konmaktadır.

Servikal kanaldan geçip vajene prolabe olan bir myomun tanısı ise genellikle muayene ve ultrasonografi ile kolaylikla konur. Ancak özellikle kalın bir pedinkülü olan bir poliple kolaylıkla karışabilir (2). Ayırıcı tanıda servikal polip, prolabe endometrial polip ve prolabe uterin sarkom mutlaka düşünülmelidir. Pelvik veya transvajinal ultrasonografi ile submukoz myomların boyutları ve yapıları kolaylıkla değerlendirilmektedir. Ancak özellikle myom dejenere olduğunda diğer endometrial tümörlerden ve mol hidatiformdan ayrimda ultrasonografi yeterince etkin olmayabileceğinden,

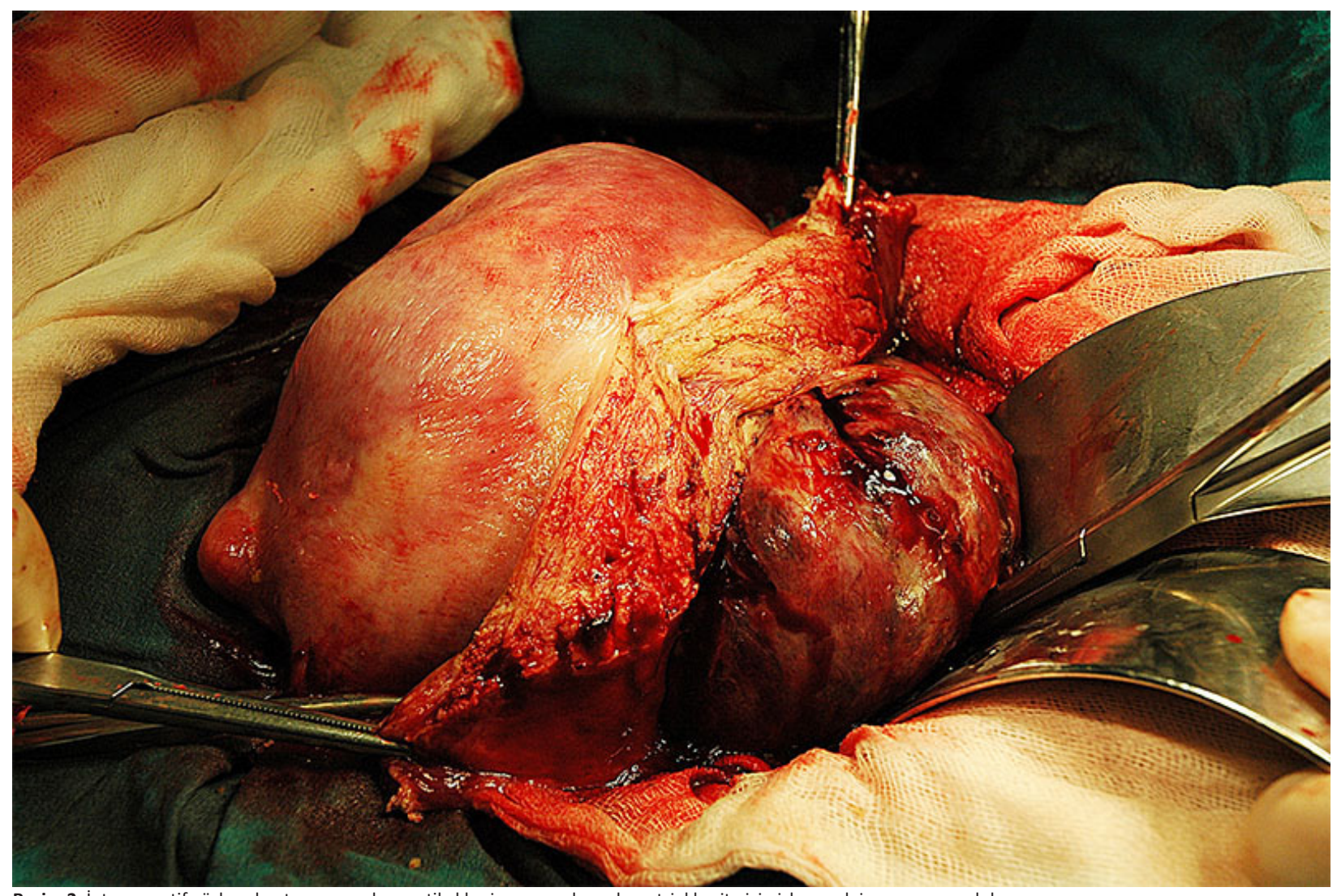


malignite șüphesi olan vakalarda veya ultrasonografik görüntülemeyi olumsuz etkileyen obezite durumlarında ikinci görüntüleme seçeneği olarak 'pelvik MRI'1 öneren otörler de bulunmaktadır (6). Rutin olarak myomların tanısı için görüntüleme yöntemlerin kullanılması mutlak gerekli değildir. Ancak ilk tercih pelvik ultrasonografi olmakla birlikte pelvik MRI da myomun büyüklüğü, pozisyonu ve pedikülün yeri konusunda daha doğru bilgi sağlayabilmektedir (7). Submukoz myom tanısını doğrulamak için operasyon öncesi kitleden insizyonel biyopsi yapmaya gerek yoktur. Ancak, lezyonun görüntüsü myom veya polip ile uyumlu değilse biopsi gerekli olabilir (8). Sunulan olguda da jinekolojik muayene ve manyetik rezonans görüntüleme sonucunda uterin sarkomdan şüphelenilmiş ve bu nedenle kitle için biyopsi alınmıştır. Al1nan biyopsinin patoloji sonucu nekrotik materyal olarak rapor edilmiştir.

Pedinküllü submüköz myomlar, vajene prolabe olduklarında eğer şikayete neden olurlarsa tipik olarak vajinal myomektomi ile kolaylıkla çıkartılırlar (9). Literatürde bildirilen vajenden çıkarılan myomların ortalama büyüklükleri $50 \mathrm{~mm}$ 'dir. Pedinkülü transservikal olarak kesilerek çıkarılan en büyük submüköz myom ise $81 \mathrm{~mm}$ olarak bildirilmektedir (10). Fakat bizim olgumuzda olduğu gibi, vajeni tamamiyle dolduran, sarkom şüphesi olanlarda, frajil myomlarda vajinal yaklaşım yeterli olmayıp, abdominal yaklaşım gerekebilir. Sunulan olguda pedikül kalın olduğundan ve kitle vajene duvarlarına oturmuş olduğundan kitlenin çıkartılması için tek başına abdominal yaklașım bile yeterli olmamıștır. Zira, vajende lokalize olan enfekte myom dokusunu abdominal yolla çıkartmaya çalışmak ameliyat sahasını gereksiz yere kontamine edeceğinden, en doğru yaklaşım myomun vajende olan kismının vajinal yolla çıkartılmasıdır. Diğer yandan sunulan olguda olduğu gibi büyük myomların vajinal yoldan çıarılmaya zorlanması da hem vajinal mukozada daha büyük hasarlanmalara hem de pelvik tabana zarar verme gibi komplikasyonlara yol açabilir.

Sonuç olarak bu denli büyük boyutlara ulaşan vajene doğmuş myom vakalarındaki cerrahi yaklaşımın vajinal veya abdominal yoldan yapılması myomun lokalizasyonu, boyutları ve pedinkülünün kalınlığı değerlendirilerek karar verilmelidir. Hasta için en uygun yolla ve uygun teknikle myom çıkarılmalıdır.

\section{KAYNAKLAR}

1. Panageas E, Kier R, McCauley T, McCarthy S. Submucosal uterine leiomyomas: diagnosis of prolapse into the cervix and vagina based on MR imaging. AJR 1992; 159:555-8

2. Golan A, Zachalka N, Lurie S, et al. Vaginal removal of prolapsed pedunculated submucous myoma: a short, simple, and definitive procedure with minimal morbidity. Arch Gynecol Obstet 2005;271:11-3

3. Faivre E, Surroca MM, Deffieux X, Pages F, Gervaise $A$, Fernandez H. Vaginal myomectomy: literature review. J Minim Invasive Gynecol. 2010;17:154-60.

4. Dicker D, Feldberg D, Dekel A, et al. The management of prolapsed submucous fibroids. Aust N Z J Obstet Gynaecol 1986;26:308-11

5. Zimmermann A1, Bernuit D, Gerlinger C, Schaefers $M$, Geppert K. Prevalence, symptoms and management of uterine fibroids: an international internet-based survey of 21,746 women. BMC Womens Health. 2012;12:6.

6. Shiota M1, Kotani Y, Umemoto M, Tobiume T, Hoshiai $H$. Estimation of preoperative uterine weight in uterine myoma and uterine adenomyosis Asian J Endosc Surg. $2012 ; 5: 123-5$

7. Parker WH. The utility of MRI for the surgical treatment of women with uterine fibroid tumors. Am J Obstet Gynecol 2012;206:31-6

8. McCluggage WG, Alderdice JM, Walsh MY. Polypoid uterine lesions mimicking endometrial sarcoma. J Clin Pathol 1999;52:543-6

9. Ikechebelu J, Eleje G, Okpala B, et al. Vaginal myomectomy of a prolapsed gangrenous cervical leiomyoma. Nigerian Journal of Clinical Practice 2012;15:358-60

10. Rolli R1, Favilli A, Acanfora MM, Scuderi G, Di Renzo GC, Gerli S. Vaginal myomectomy is a safe and feasible procedure: a retrospective study of 46 cases. J Obstet Gynaecol Res. 2012;38:1201-5. 